\title{
UM OLHAR PARA A DIMENSÃO INFRAESTRUTURA COMO UMA DAS CONDIÇÕES OBJETIVAS POSSIBILITADORAS DA QUALIDADE EM ESCOLAS PÚBLICAS
}

\author{
UNA MIRADA A LA DIMENSIÓN DE INFRAESTRUCTURA COMO UNA DE \\ LAS CONDICIONES OBJETIVAS DE CALIDAD POSIBILITANTE EN LAS \\ ESCUELAS PÚBLICAS
}
A LOOK TO THE INFRASTRUCTURE DIMENSION AS ONE OF THE OBJECTIVE CONDITIONS ENABLERS OF QUALITY IN PUBLIC SCHOOLS

\author{
Claudia Pereira de Pádua SABIA ${ }^{1}$ \\ Mara Regina Lemes de SORDI ${ }^{2}$
}

RESUMO: As avaliações externas e seus indicadores vêm responsabilizando unilateralmente a escola e seus profissionais pelos resultados atingidos por estudantes, desconsiderando o peso das condições objetivas para o desenvolvimento do trabalho escolar, o que afeta a autoestima dos professores e gestores. Objetiva-se com este estudo, identificar e analisar as condições objetivas das escolas públicas do ensino fundamental de uma diretoria de ensino, com destaque à dimensão infraestrutura. Para tal, a metodologia utilizada envolve abordagem quanti-qualitativa e conjuga pesquisas bibliográficas, análise documental e aplicação de questionários. A coleta de dados consistiu em questionário google docs encaminhado aos professores dos anos finais do Ensino Fundamental de uma Diretoria de Ensino do oeste paulista. Como resultados, identificamos que das 47 escolas pesquisadas, 22 (46,80\%) possuem infraestrutura elementar e $24(51,06 \%)$ podem ser enquadradas como infraestrutura básica; nenhuma adequada e nenhuma avançada, que seria o nível mais elevado da escala de infraestrutura proposta por Soares Neto, Jesus, Karino e Andrade (2013). Os indicadores da dimensão infraestrutura evidenciam que as condições objetivas são predominantemente precárias, o que compromete o desenvolvimento do trabalho docente. Entretanto, as condições objetivas são subestimadas nos processos avaliativos, que culpabilizam apenas um dos polos, ou seja, a escola e seus profissionais, pelos resultados das avaliações externas, e não responsabilizam o Estado pelo seu não oferecimento. Consideramos a necessidade da discussão dos resultados avaliativos na perspectiva de uma responsabilização compartilhada, ou seja, participativa, em que o poder público se reconheça no processo de melhoria da qualidade, assumindo a parte que lhe cabe.

PALAVRAS-CHAVE: Qualidade da escola. Condições objetivas. Infraestrutura escolar. Responsabilização educacional participativa. Avaliação externa. Avaliação Institucional Participativa (AIP).

\footnotetext{
1 Universidade Estadual de Campinas (UNICAMP), Campinas - SP - Brasil. Professora da Faculdade de Filosofia e Ciências (UNESP). Doutorado em Educação (UNESP). Estágio de Pós-Doutorado em Desenvolvimento (PPGE). ORCID: https://orcid.org/0000-0001-8173-6420. E-mail: claudia.sabia@unesp.br 2 Universidade Estadual de Campinas (UNICAMP), Campinas - SP - Brasil. Professora Associada do Departamento de Estudos e Práticas Culturais (DEPRAC) da Faculdade de Educação. Doutorado em Educação (UNICAMP). ORCID: https://orcid.org/0000-0003-1216-7185. E-mail: maradesordi14@gmail.com
} 
RESUMEN: Las evaluaciones externas y sus indicadores han hecho unilateralmente que la escuela y sus profesionales sean responsables de los resultados alcanzados por los estudiantes, sin tener en cuenta el peso de las condiciones objetivas para el desarrollo del trabajo escolar, lo que afecta la autoestima de los maestros y administradores. El objetivo de este estudio es identificar y analizar las condiciones objetivas de las escuelas primarias públicas en una directora de enseñanza con énfasis en la dimensión de infraestructura. Para este fin, la metodología utilizada implica un enfoque cuanti-cualitativo y combina investigación bibliográfica, análisis de documentos y aplicación de cuestionarios. La recopilación de datos consistió en un cuestionario de documentos de Google enviado a los maestros en los últimos años de la escuela primaria por una dirección de enseñanza en el oeste de São Paulo. Como resultado, identificamos que de las 47 escuelas encuestadas, 22 (46.80\%) tienen infraestructura primaria, 24 (51.06\%) pueden clasificarse como infraestructura básica, ninguna adecuada, ninguna avanzada que sería el nivel más alto de la escala de infraestructura propuesto por Soares Neto, Jesus, Karino y Andrade (2013) Los indicadores de la dimensión de infraestructura muestran que las condiciones objetivas son predominantemente precarias, lo que compromete el desarrollo del trabajo docente. Sin embargo, las condiciones objetivas se subestiman en los procesos de evaluación que culpan solo a uno de los polos, es decir, la escuela y sus profesionales, por los resultados de las evaluaciones externas y no responsabiliza al Estado por no ofrecer-los. Consideramos la necesidad de discutir los resultados de la evaluación en la perspectiva de una responsabilidad compartida, es decir, participativa, en la que el poder público se reconozca en el proceso de mejora de la calidad, asumiendo su parte.

PALABRAS CLAVE: Calidad Escolar. Condiciones objetivas. Infraestructura escolar. Responsabilidad educativa participativa. Evaluación externa. Evaluación Institucional Participativa (AIP).

ABSTRACT: External evaluations and their indicators have unilaterally made the school and its professionals responsible for the results achieved by students, disregarding the weight of objective conditions for the development of school work, which affects the self-esteem of teachers and administrators. The aim of this study is to identify and analyze the objective conditions of public elementary schools from a teaching board with emphasis on the infrastructure dimension. To this end, the methodology used involves a quantiqualitative approach and combines bibliographic research, document analysis and application of questionnaires. The data collection consisted of a google docs questionnaire sent to teachers in the final years of elementary school from a teaching directorate in the west of São Paulo. As a result, we identified that of the 47 schools surveyed, 22 (46.80\%) have elementary infrastructure, 24 (51.06\%) can be classified as basic infrastructure, none adequate, none advanced that would be the highest level of the infrastructure scale proposed by Soares Neto, Jesus, Karino and Andrade; (2013). The indicators of the infrastructure dimension show that the objective conditions are predominantly precarious, which compromises the development of teaching work. However, the objective conditions are underestimated in the evaluation processes that blame only one of the poles, that is, the school and its professionals for the results of external evaluations and does not hold the State responsible for not offering them. We consider the need to discuss the evaluation results in the perspective of shared, that is, participatory, accountability, in which the public power recognizes itself in the quality improvement process, assuming its part.

RIAEE - Revista Ibero-Americana de Estudos em Educacão, Araraquara, v. 16, n. 1, p. 127-152, jan/mar 2021. e-ISSN: 1982-5587 
KEYWORDS: School quality. Objective conditions. School infrastructure. Participatory educational accountability. External evaluation. Participatory Institutional Assessment (AIP).

\section{Introdução}

$\mathrm{O}$ atual contexto educacional evidencia a hegemonia das avaliações de larga escala (externas) sobre os demais níveis de abordagem da avaliação (avaliação da aprendizagem) dos estudantes na sala de aula e (avaliação institucional) da escola.

Conforme Fischer (2010), os processos avaliativos constituem um elemento fundamental da ação educativa. Entretanto, a avaliação não é um momento final do ato pedagógico e, sim, um elemento integrante do seu processo. Para a autora:

[...] o que se questiona é o fato de que, a partir da década de noventa do século XX, a implantação de determinadas políticas e o sucesso do atingimento de metas passaram a determinar não só o conteúdo a ser ensinado, mas também o modo de um estudante responder as questões de uma prova, ou até a forma como deve pensar. E o mais grave, no dia a dia da sala de aula, o sentido pedagógico do processo ensinar a prender corre o risco de ficar focado muito mais nos resultados do que nos processos. Educadores, pais e professores precisam ter consciência de que a obsessão pelo resultado pode obscurecer a importância do processo (FISCHER, 2010, p. 39).

As avaliações de larga escala e sua perspectiva de avaliação uni/bidimensional buscam expressar o quantum de qualidade que cada escola possui, ignorando as variáveis que afetam os resultados das aprendizagens dos estudantes.

O processo de ensino-aprendizagem é complexo e exige a interação de diversos fatores para ser realizado de forma adequada. Requer desde um corpo docente qualificado até condições de infraestrutura escolar favorável, o que inclui materiais didáticos, equipamentos e estruturas físicas apropriadas. Sem o suporte suficiente para o desenvolvimento do seu trabalho, a atuação do professor fica comprometida, ou seja, o suporte institucional é fundamental para que o professor possa desenvolver um bom trabalho educacional.

As avaliações externas (Prova Brasil ${ }^{3}$ e SARESP $^{4}$ ) e seus indicadores (IDEB ${ }^{5}$ e IDESP $^{6}$ ) vêm responsabilizando unilateralmente a escola e seus profissionais pelos resultados atingidos, desconsiderando as condições objetivas para o desenvolvimento do trabalho na escola e afetando a autoestima dos professores e gestores.

\footnotetext{
${ }^{3}$ Avaliação Nacional do Rendimento Escolar.

${ }^{4}$ Sistema de Avaliação do Rendimento Escolar do Estado de São Paulo.

5 Índice de Desenvolvimento da Educação Básica.

6 Índice de Desenvolvimento da Educação do Estado de São Paulo.
} 
Este artigo faz parte de estudo de pós-doutorado sobre as condições objetivas das escolas públicas paulistas dos anos finais do ensino fundamental de uma Diretoria de Ensino da Região oeste do Estado de São Paulo. O objetivo deste trabalho será identificar as condições objetivas da dimensão infraestrutura das escolas pesquisadas para que sejam consideradas como componentes da qualidade em processos avaliativos coerentes com os contextos em que se realizam. Portanto, não se restringindo exclusivamente aos resultados dos testes padronizados e aos índices decorrentes (IDEB e IDESP), numa perspectiva de avaliação bidimensional que ignora a impossibilidade de se isolar ou exercer controle sobre todas as variáveis que afetam os resultados.

Para o desenvolvimento deste trabalho, iniciaremos com as condições objetivas das escolas, o processo de responsabilização educacional, a metodologia, a apresentação, discussão e análise dos dados e as considerações finais.

\section{Condições objetivas das escolas}

Entendemos que as condições objetivas são componentes da qualidade das escolas desta Diretoria de Ensino que precisam ser levadas em conta em seus processos avaliativos. A qualidade de um estabelecimento de ensino deve abarcar três categorias: Projeto Político Pedagógico (PPP), corpo social e a infraestrutura. Parece consensual a importância do PPP e igualmente se valoriza o corpo social da escola como fundamental para sustentar o PPP. Temos visto que a categoria da infraestrutura é a menos valorizada e que seu peso passa quase desapercebido no processo de qualificação da escola. Disso deriva nosso interesse em desvelar as condições objetivas desapercebidas e as efetivamente existentes em determinadas escolas, com destaque à infraestrutura e seus indicadores.

Considerando a forte presença dos reformadores empresariais na política educacional, que conseguiram a criação do IDEB como indicador que afeta o entendimento do que seja qualidade, defendemos a necessidade de assumir e de adjetivar a qualidade com o vocábulo 'social', que entendemos necessário à escola pública e que exige infraestrutura e condições de trabalho adequadas ao desenvolvimento das aprendizagens. Entendemos que a finalidade da escola abarca outras dimensões da formação humana que extrapolam a dimensão cognitiva e devem ser consideradas na avaliação educacional.

Apoiamos em Sordi (2017, p. 86) ao afirmar que a "qualidade social na escola pública deve orientar-se pela construção de um mundo melhor, isto é, um mundo mais educado, mais evoluído culturalmente e socialmente mais justo.” Para a autora, estes educadores estão 
"filiados e unidos em torno de uma concepção de qualidade ampliada, detentora de pertinência social, uma qualidade includente e democrática, construída com os atores, com a comunidade e regida pela ideia do bem público".

Explicitamos também a referência ao SINAES, pois este serviu de modelo para a construção de um olhar ampliado, para a discussão da qualidade da educação superior e orientou os processos de regulação, ou seja, autorização, reconhecimento, renovação de reconhecimento de cursos superiores. Na sua primeira fase foi considerada ideia vanguardista, mas depois acabou se distanciando de determinada concepção de educação que tinha compromisso com a formação humana, dadas as pressões de ordem político-econômicas que foram metamorfoseando seus princípios. Em que pese este retrocesso, a Rede Municipal de Campinas recupera a base filosófica do SINAES para conceber e implementar o processo de Avaliação Institucional Participativa (AIP), que se contrapõe ao processo de responsabilização (accountability) da escola e de seus profissionais unilateralmente pelos resultados obtidos nas avaliações de larga escala, ou seja, propõe a responsabilidade compartilhada entre poder público e atores da comunidade escolar para a construção da qualidade educacional.

No que concerne ao recorte deste estudo, cabe desvelar o que se entende por condições objetivas para iluminar o debate sobre a qualidade da escola, e assim a responsabilização compartilhada traz à cena outros atores e fatores que afetam a discussão sobre qualidade.

Conforme Betini (2009):

[...] as condições objetivas, concretas, são aquelas que já existem, aquelas que na escola pública são providas, dadas pelo poder público, implícitas nas políticas públicas educacionais. Seguramente, existirão outras que podem ser conquistadas e outras que podem ser transformadas pela ação do coletivo da escola e que passam a se incorporar àquelas já existentes. Afinal, as condições objetivas materiais, tanto determinam como podem ser determinadas pelo homem (BETINI, 2009, p. 91).

Paro (2012, p. 598) menciona que as autoridades governamentais responsáveis pelos sistemas de ensino, em seus discursos, concentram a atenção sobre a formação dos profissionais da educação como o problema mais importante da qualidade do ensino fundamental. Para o autor, "pode ser uma boa forma de obnubilar os reais determinantes do fracasso escolar, ou seja, as condições objetivas de trabalho". Conforme o Dicionário Aurélio (2020), obnubilar significa "escurecer, fazer com que se torne obscuro, como se observado por entre nuvens". Pelo que apreendemos, o autor considera as condições objetivas de trabalho como uma das causas do fracasso escolar. 
Embora não se negue a necessidade de melhor qualificar os professores, especialmente a partir de formação em serviço (mas também não se pode deixar de, paralelamente, passar a aproveitar melhor suas potencialidades, frequentemente subutilizadas), é no conjunto dos fatores constitutivos das práticas presentes no interior da escola que devem ser buscadas as causas de seus problemas e as fontes de suas soluções: no montante e na utilização dos recursos materiais e financeiros; na organização do trabalho; nos métodos de ensino; na formação, desempenho e satisfação do pessoal escolar; nos currículos e nos programas; no tamanho das turmas; na adequação de edifícios; na utilização de tempos e espaços; na distribuição da autoridade e do poder na instituição; na relação com os membros da comunidade e na importância que se dê a seu papel como cidadãos/sujeitos; no planejamento, na avaliação e no acompanhamento constante das práticas escolares; enfim, em tudo que diz respeito à estrutura e ao funcionamento da escola. [...] (PARO, 2003, p. 99 apud PARO, 2012, p. 598-599).

Em síntese, Paro (2012), considera como condições objetivas tudo o que diz respeito à estrutura e ao funcionamento da escola. A pesquisa de Tomaz; Silva (2017), intitulada "O que as escolas fazem que os testes estandardizados desprezam na avaliação da qualidade? Ouvindo as escolas", traz que:

[...] Não menos importantes foram as contribuições coletadas sobre as condições objetivas de trabalho na escola, que indicaram a necessidade de as redes considerarem: 1) número de alunos coerente com a proposta de atendimento; 2) carga horária docente que respeite tempos sem alunos, para trabalho na escola; 3)presença no aluno no contra turno; 4) presença de estagiários e cuidadores na escola; 5) presença de docentes para ministrar aula e de demais funcionários de apoio; 6) estrutura física adequada. Estas condições, aliadas ao cuidado com a formação para o trabalho docente, são fundamentais para o desenvolvimento das práticas anteriormente citadas, pois segundo os professores de escola observada "a prática docente em condições precárias compromete o ensino e, como consequência, a aprendizagem dos alunos" (TOMAZ; SILVA, 2017, p. 163, grifo nosso).

Buscamos enfatizar que as condições objetivas não têm sido consideradas como fatores que afetam o desempenho das escolas e que são publicizadas sob a forma de rankings, com o resultado das escolas no IDEB ou IDESP. Por outro lado, pesquisas vão apontando que as condições precárias comprometem o ensino e aprendizagem dos alunos. Soares (2013, p. 181) destaca "a complexa relação entre o valor do IDEB da escola e suas características contextuais definidas pelo perfil do aluno e pelas condições de oferta escolar". Oliveira; Pereira Junior (2016) elaboraram trabalho denominado "Indicadores do trabalho docente: múltiplas associações no contexto escolar"' em que apresentam indicadores para representarem os aspectos do trabalho escolar docente na educação básica a partir de uma 
pesquisa realizada em sete estados brasileiros. Destacamos aspectos relacionados à nossa discussão sobre as condições objetivas:

Acrescenta-se ainda que o maior efeito total na satisfação profissional foi
exercido pela frequência de desenvolvimento de atividades com colegas de
trabalho. Entretanto, ao se considerarem, de forma concomitante, as
condições da sala de aula e da unidade educacional, o efeito conjunto
dessas condições (0,233) se torna o principal aspecto relacionado à
satisfação dos professores com a profissão. Por mais óbvio que possa
parecer, o investimento em infraestrutura e equipamentos é de suma
importância para a melhoria da educação, pois não só permite melhor
acolhimento às crianças e jovens que frequentam a escola, como também se
traduz em melhores condições de trabalho para os que nela atuam. Diante
das desigualdades regionais deste país, é muito importante termos em vista
que um padrão mínimo de atendimento escolar deveria ser garantido; o
Custo Aluno Qualidade (CAQ), já aprovado em lei, poderia ser uma medida
relevante nessa direção (OLIVEIRA; PEREIRA JÚNIOR, 2016, p. 874,
grifo nosso).

Segundo Pinto (2014), o sistema de ensino brasileiro se propõe a formar cidadãos críticos e autônomos e, portanto, "há um grande impacto sobre a demanda de insumos. Dificilmente se consegue esse objetivo com muitos alunos por turma e professores que só sabem seguir apostilas.” (PINTO, 2014, p. 10). O autor apresenta ainda estudos sobre os insumos de Hedges, Laine e Grenwald (1994), que mostram que existe uma forte correlação entre insumos escolares e desempenho dos estudantes.

Soares Neto, Jesus, Karino e Andrade (2013) apresentam pesquisa de Hattie (2009) que verifica a influência da infraestrutura no desempenho dos estudantes, considerando vários países, entre os quais Estados Unidos e Nova Zelândia. Neste estudo foi argumentado que a maior fonte de variância está, na verdade, dentro das escolas e não entre as escolas. Este dado é consistente em países desenvolvidos, cuja infraestrutura escolar se apresenta de forma equitativa entre as escolas, não podendo ser ratificado em países que possuem um sistema educacional não equitativo, como o Brasil. Neste país, a responsabilidade pela oferta da educação básica é dividida entre estados e municípios em um cenário de grande desigualdade regional e com a enorme disparidade existente entre as diversas redes de ensino.

Os autores citados buscaram identificar qual a infraestrutura adequada para que uma escola tenha condições de oferecer uma educação de melhor qualidade. Os autores criaram uma escala para medir a infraestrutura escolar, utilizando como ferramenta a Teoria de Resposta ao Item (TRI) e se baseando em informações referentes às escolas no Censo Escolar da Educação Básica de 2011. Os autores estabeleceram quatro categorias: Elementar, Básica, Adequada e Avançada. O estudo apresenta como resultados que " $44,5 \%$ das escolas 
brasileiras encontram-se na categoria elementar, 40\% na categoria básica, 14,9\% na categoria adequada e 0,6\% em avançada" (SOARES NETO; JESUS; KARINO; ANDRADE; 2013, p. 90-92).

Conforme abordamos anteriormente, várias pesquisas: Paro (2012); Soares Neto, Jesus, Karino e Andrade (2013); Pinto (2014); Oliveira e Pereira Junior (2016), dentre outras, informam a complexa relação de variáveis que interferem no desempenho dos estudantes nos testes padronizados e, particularmente, no desenvolvimento de aprendizagens ampliadas, orientadas por uma matriz de formação humana, ou seja, outras qualidades da escola pública. No entanto, tem prevalecido a lógica do ranqueamento, exacerbando o controle vertical sobre a escola, sem considerar as condições objetivas em que a escola está atuando. No tópico seguinte, apresentaremos o processo de responsabilização educacional e suas várias nuances.

\section{O Processo de responsabilização educacional}

A accountability é uma política de responsabilização com atribuição de consequências para os agentes escolares. Podemos citar como exemplos as políticas de responsabilização educacional: a bonificação docente - em função do atingimento de metas; a premiação de alunos ou escolas - com destaque o desempenho positivo nas avaliações em larga escala; e a aplicação de sanções e intervenções em escolas que não tenham atingido as metas determinadas.

Conforme Bonamino e Sousa (2012), quando as consequências dessas políticas "são apenas simbólicas, elas são chamadas de low stakes ou de responsabilização branda. Já quando as consequências são sérias, elas são chamadas de high stakes ou de responsabilização forte" (CARNOY; LOEB, 2002; BROOKE, 2006 apud BONAMINO; SOUSA, 2012, p. 375).

Destacamos que no Brasil temos tanto as sanções sérias, ou seja, materiais, como as simbólicas. Citamos como exemplo de sanções materiais a bonificação docente ${ }^{7}$ e a liberação de recursos às escolas condicionado ao cumprimento de metas ${ }^{8}$, e simbólicas com a divulgação dos resultados publicamente em rankings que afetam a autoestima dos profissionais da escola, entre outras coisas.

${ }^{7}$ Conforme Capocchi (2017), baseado em dados de 2014, dos vinte e sete estados brasileiros, treze já possuíam algum tipo de bonificação docente.

${ }^{8}$ Em matéria publicada recentemente no Jornal Folha de São Paulo, a respeito do FUNDEB, os autores informam que têm avançado as propostas que reservam parte deste recurso extra para ser distribuído com base na adoção de boas práticas educacionais e, também, a partir da melhoria de indicadores educacionais (PUPO; SALDANÃ, 2020).

RIAEE - Revista Ibero-Americana de Estudos em Educação, Araraquara, v. 16, n. 1, p. 127-152, jan./mar. 2021. e-ISSN: 1982-5587 
Afonso (2012) considera o seu significado ligado a uma forma gerencialista de prestação de contas:

[...] o significado do vocábulo accountability indica frequentemente uma forma hierárquico-burocrática ou tecnocrática e gerencialista de prestação de contas que, pelo menos implicitamente, contém e dá ênfase a consequências ou imputações negativas e estigmatizantes, as quais, não raras vezes, consubstanciam formas autoritárias de responsabilização das instituições, organizações e indivíduos. Aliás, mesmo quando estas caraterísticas são menos vincadas, o certo é que a representação social que acentua o seu carácter punitivo tem sido um importante obstáculo à conceptualização de formas mais avançadas e alternativas de accountability (AFONSO, 2012, p. 472).

Conforme Brooke (2006), esta exigência por maiores informações sobre os resultados dos sistemas escolares tem sido respondida pela implementação de políticas de accountability, ou seja, de responsabilização mediante as quais se tornam públicas as informações sobre o trabalho das escolas, e consideram-se os gestores e outros membros da equipe escolar como corresponsáveis pelo nível de desempenho alcançado pela instituição.

Ressaltamos que o nosso interesse em realizar o mapeamento das condições objetivas das escolas públicas paulistas desta Diretoria consiste em fornecer subsídios para a discussão de seus resultados avaliativos na perspectiva de uma responsabilização compartilhada, ou seja, participativa, em que o poder público se reconheça no processo de melhoria da qualidade, assumindo a parte que lhe couber. Por outro lado, a repercussão das condições objetivas poderá contribuir para diminuir as resistências dos professores aos processos de avaliação que apenas cobram e responsabilizam-nos. Apoiamos em Sordi para explicitar o sentido da responsabilização participativa. Conforme a autora:

[...] a responsabilização participativa assenta-se numa visão de avaliação dialógica, fruto de um processo intersubjetivo rico e plural em que se buscam acordos consensuados de modo transparente e corajoso, negociandose sentidos, tempos, estratégias e metas. Atores se unem em torno do Bem Comum e, juntos, constroem o futuro pelas decisões que tomam no presente (SORDI, 2017, p. 93).

A responsabilização participativa se contrapõe aos processos de responsabilização unilateral e vertical que culpabilizam escolas, gestores e professores pelos resultados insatisfatórios obtidos nas avaliações externas. Segundo Freitas (2016, p. 128):

O Brasil fez a escolha por uma política nacional imediatista de controle e responsabilização verticalizada de suas escolas, professores e alunos como método para aprimorar a qualidade da educação, perdendo a oportunidade de apostar em uma política consistente de responsabilização participativa. A 
política adotada tem por princípio promover a concorrência entre escolas e entre os profissionais da área, baseada na ideia de que médias mais altas seriam um indicador de bom ensino.

Ainda segundo Freitas (2013), há evidências de que o desenho desta política educacional baseada em accountability tem origem nos Estados Unidos e, portanto, produziu efeitos lá dentro. Hoje há uma farta literatura naquele país que examina as consequências da política de responsabilização.

O trabalho mais conhecido foi o de Ravitch (2011), que analisa detalhadamente a reforma educacional americana expressa na No Child Left Behind (NCLB), que se baseava na possibilidade de as famílias escolherem a melhor escola, levando consigo para a escola escolhida as subvenções públicas oferecidas pelo Estado. Visando facilitar a escolha, foi estimulada a competição entre as escolas, para que captassem mais alunos e mais recursos. $\mathrm{O}$ sistema de escolhas é baseado nos resultados dos testes padronizados, estabelecendo ranking entre as instituições escolares. Conforme a autora:

[...] a (NCLB) mudou a natureza das escolas públicas do país, tornando os escores de testes padronizados a principal forma de medir a qualidade escolar. A ascensão ou queda dos escores em leitura ou matemática se tornou a variável crítica para julgar os estudantes, professores, diretores e escolas. [...] No fim eu percebi que as novas reformas tinham tudo a ver com mudanças estruturais e com a responsabilização, e nada que ver com a substância do aprendizado. A responsabilização não faz sentido quando ela sabota os objetivos maiores da educação (RAVITCH, 2011, p. 31-32).

Pelo que pudemos apreender, Ravitch (2011) destaca que a responsabilização não está ajudando as escolas americanas, pelo contrário, comprometendo ainda mais a qualidade do ensino ao focar as habilidades básicas. A autora considera que o problema com a responsabilização baseada em testes é que impõe sérias consequências para crianças, educadores e escolas com base em escores que podem refletir um erro de mensuração, um erro estatístico, uma variação aleatória ou um conjunto de fatores ambientais ou atributos dos estudantes. Em síntese, afirma que os testes agora em uso não são adequados por si só para a tarefa de avaliar a qualidade das escolas e professores.

Karp (2012) chama atenção para as sanções cada vez mais direcionadas aos professores. Alimentado pelo sistema de responsabilização baseado em testes e punições da NCLB, o discurso dominante se centrou nos fracassos da escola pública e na necessidade de reduzir o poder dos educadores sobre as políticas escolares para aumentar o poder dos gerentes empresariais e das burocracias políticas. Ele considera que estas estratégias mudaram a maneira como as escolas e as salas de aula funcionam no cotidiano e refletem-se nos ataques 
contra as negociações coletivas e os sindicatos dos professores e na permanente crise de financiamento. Pelo que pudemos apreender, o autor considera um ataque sem precedentes à educação pública e sua substituição por um sistema baseado no mercado.

No caso brasileiro não tem sido diferente. Leher (2014) identifica a atuação do Movimento Todos Pela Educação (TPE), que representa o setor empresarial.

Já no governo Lula da Silva, em 2006, expressando a liderança do setor financeiro no bloco no poder e no Estado Maior do Capital, os bancos convocaram uma nova coalizão, mais ampla e orgânica, para interferir na educação, o já apresentado TPE. Atuando na forma de partido, o movimento reuniu e agregou as iniciativas burguesas na educação até então dispersas, estabeleceu uma agenda na forma de metas e compromissos de todos pela educação (inicialmente 10 Causas e 26 Compromissos, depois sintetizados) e organizou um robusto aparato de circulação de suas ideias nos grandes meios de comunicação, situação facilitada pela adesão dos mesmos ao TPE (LEHER, 2014, p. 4).

Freitas (2007) destaca a pressão que esses acordos entre prefeitos e o governo federal iriam gerar nas escolas e professores.

O mais grave é o fortalecimento da ideia de que seria possível, a partir de sistemas de larga escala centralizados em Brasília ou em uma capital, reorientar escolas específicas, a distância, por exposição dos resultados à sociedade e acordos com prefeitos. Pode-se imaginar a pressão autoritária, verticalizada, que os acordos assinados entre os prefeitos e o governo federal, para assumir metas do IDEB para seu município e obter verbas, vão gerar nas escolas e em seus profissionais (FREITAS, 2007, p. 973).

A pressão pelos resultados para obtenção de bônus e para evitar sanções tem provocado uma série de consequências para a educação brasileira. Várias pesquisas têm contribuído para a discussão dos seus efeitos, apontando suas contradições e ineficiência para alavancarem a qualidade de ensino. Destacamos o processo de responsabilização educacional americano e apresentamos suas consequências, pois é neste país que o Brasil tem buscado a referência para a implantação do processo de responsabilização educacional. Portanto, estamos implantando no país uma política educacional que já teve sua ineficácia comprovada na educação norte-americana e que agravou ainda mais a crise da educação pública naquele país. Após abordarmos o processo de responsabilização e a forma sorrateira com que trata (ou não trata) as condições objetivas que deveriam sustentar o trabalho escolar, apresentaremos a metodologia e na sequência a apresentação e discussão dos dados. 


\section{Metodologia}

A pesquisa foi desenvolvida em uma abordagem quanti-qualitativa. Esta abordagem destaca a potência e pertinência dos métodos qualitativos para fazerem a ponte com a realidade, o contexto, o processo, e o papel dos métodos quantitativos nas pesquisas com grande número de casos. A combinação dos métodos pode estimular ainda mais a investigação qualitativa, desde que os resultados impulsionem o pesquisador ao questionamento mais aprofundado do fenômeno investigado. Conforme Minayo (2000):

[...] a dicotomia que se estabelece na prática, de um lado, deixa à margem relevâncias e dados que não podem ser contidos em números, e de outro lado, às vezes contempla apenas os significados subjetivos, omitindo a realidade estruturada (MINAYO, 2000, p. 28).

A pesquisa abarcou as 47 escolas que oferecem vagas aos alunos dos anos finais do ensino fundamental ( $6^{\circ}$ ao $9^{\circ}$ ano) regular pertencentes a uma Diretoria de Ensino do oeste paulista. Os procedimentos utilizados na investigação foram a pesquisa bibliográfica, a pesquisa documental e a coleta de dados.

A pesquisa documental consistiu no levantamento de dados disponíveis no site do Instituto Nacional de Estudos e Pesquisas Educacionais Anísio Teixeira (INEP), no site da Secretaria Estadual de Educação de São Paulo (SEE/SP) e dados obtidos junto à Diretoria de Ensino pesquisada, ou seja, planilha no Excel contendo dados de infraestrutura das escolas pesquisadas enviadas ao Censo Escolar.

$\mathrm{Na}$ coleta de dados foi utilizado o questionário google docs para complementar os dados obtidos na pesquisa documental. A Diretoria de Ensino pesquisada nos forneceu e-mail das 47 escolas pesquisadas. Encaminhamos link do formulário no período de finalização do ano letivo, ou seja, em dezembro de 2019, para que fosse enviado aos professores que trabalharam nos anos finais do ensino fundamental neste ano. $\mathrm{O}$ formulário ficou aberto para preenchimento pelo período de 30 dias. Informamos que de 844 docentes obtivemos 191 respostas, ou seja, 22,74\%. Na atualidade, o índice de retorno de questionários está entre $15 \mathrm{e}$ 20\%. Para apresentar as respostas abertas, utilizaremos a abreviação de Professor (P), com o respectivo número do respondente $(\mathrm{P} 1, \mathrm{P} 2, \mathrm{P} 3, \mathrm{P} 4 \ldots . \mathrm{P} 192)$. 


\section{Apresentação e discussão dos dados}

O nosso estudo abarca os dados das 47 escolas da Rede Estadual Paulista que oferecem os anos finais do Ensino Fundamental (EF) na Diretoria de Ensino de Marília (DRM). Esta Unidade é uma das 91 Diretorias do Estado de São Paulo.

A Rede Estadual Paulista compartilha ${ }^{9}$ com os municípios a oferta do ensino fundamental e é responsável pela oferta do ensino médio. Conforme dados do $\operatorname{INEP}^{10}$ (2019), neste ano o total de matrículas nos anos finais do ensino fundamental foi 2.367.699. Deste total, a rede estadual atende majoritariamente os anos finais do EF, pois possui $57,53 \%$ das matrículas, enquanto a rede municipal $(22,86 \%)$ e a rede privada $(19,61 \%)$. Diferentemente dos anos iniciais do EF, que do total de 3.041.488 matrículas, a rede municipal atende a maior parcela do alunado $(57,77 \%)$, a rede estadual $(20,77 \%)$, a rede privada $(21,44 \%)$, e o restante com uma ínfima participação da rede federal.

Esta Diretoria possui 60 escolas sob sua responsabilidade. Apenas 10 escolas oferecem os anos iniciais do ensino fundamental (3.174 matrículas nos municípios de Marília e Oriente) em 2019. Embora estes municípios tenham aderido ao processo de municipalização do ensino nos anos iniciais do Ensino Fundamental (EF), a Rede Estadual manteve 9 escolas em Marília e uma em Oriente, compartilhando a oferta. A DRM possui 47 escolas que oferecem os anos finais do EF, indicando que o processo de municipalização dos anos iniciais prevaleceu em relação aos anos finais nos municípios abrangidos por esta Diretoria. Informamos também que ela oferece ainda o Ensino Médio e a modalidade de ensino de Educação de Jovens e Adultos (EJA) para os anos finais do (EF) e Ensino Médio.

Tabela 1 - Número de municípios, de escolas e matrículas dos anos finais do (EF) na Diretoria de Ensino de Marília (DRM) e na Rede Privada

\begin{tabular}{l|r|r|r}
\hline Rede & Municípios & Escolas & Matrículas \\
\hline Rede Estadual (DRM) & 13 & 47 & 11.986 \\
\hline Rede Particular & 04 & 22 & 4.735 \\
\hline
\end{tabular}

Fonte: Sinopse Estatística (2019) INEP

${ }^{9}$ Artigo 211 - Parágrafo $2^{\text {o }}$ - Os Municípios atuarão prioritariamente no ensino fundamental e na educação infantil. Parágrafo $3^{\circ}$ - Os Estados e o Distrito Federal atuarão prioritariamente no ensino fundamental e médio. Parágrafo $4^{\mathrm{o}}$ - $\mathrm{Na}$ organização de seus sistemas de ensino, os Estados e os Municípios definirão formas de colaboração, de modo a assegurar a universalização do ensino obrigatório. (Constituição Federal de 1988).

106 Instituto Nacional de Estudos e Pesquisas Educacionais Anísio Teixeira (INEP) Sinopse Estatística 2019. 
A Diretoria de Ensino de Marília (DRM) é responsável pelas matrículas públicas dos anos finais do Ensino Fundamental (EF). Não temos matrículas neste segmento do EF nas Redes Municipais nos 13 municípios desta Diretoria, pois eles são responsáveis apenas pelos anos iniciais do EF. O setor privado possui 4.735 matrículas neste segmento, representando $39,50 \%$ das matrículas.

Apresentamos o decréscimo de matrículas nos anos finais do EF ocorrida nos últimos dez anos (Tabela 2). Portanto, do mesmo modo que aconteceu no estado de São Paulo, a DRM apresentou queda de matrículas neste período correspondente a 32,93\%, em números absolutos, 5.885 alunos a menos.

Tabela 2 - Matrículas dos anos finais do (EF) nas Redes Estadual e Privada nos municípios abrangidos pela Diretoria de Ensino de Marília (DRM) no ano de 2009 e 2019

\begin{tabular}{l|c|c|c|c}
\hline Municípios & $\begin{array}{c}\text { Rede } \\
\text { Estadual } \\
2009\end{array}$ & $\begin{array}{c}\text { Rede } \\
\text { Estadual } \\
2019\end{array}$ & $\begin{array}{c}\text { Rede } \\
\text { Privada } \\
2009\end{array}$ & $\begin{array}{c}\text { Rede } \\
\text { Privada } \\
2019\end{array}$ \\
\hline Álvaro de Carvalho & 265 & 197 & --- & --- \\
\hline Alvinlândia & 236 & 180 & --- & --- \\
\hline Echaporã & 448 & 299 & --- & --- \\
\hline Fernão & 114 & 121 & --- & --- \\
\hline Gália & 431 & 240 & --- & --- \\
\hline Garça & 2.290 & 1.649 & 513 & 547 \\
\hline Júlio Mesquita & 352 & 188 & --- & 5 \\
\hline Lupércio & 327 & 226 & --- & --- \\
\hline Marília & 11.053 & 7.327 & 2.911 & 3.936 \\
\hline Ocauçu & 270 & 219 & --- & --- \\
\hline Oriente & 360 & 198 & --- & --- \\
\hline Pompéia & 1.025 & 688 & 179 & 247 \\
\hline Vera Cruz & 700 & 454 & --- & --- \\
\hline TOTAL & 17.871 & 11.986 & 3.603 & 4.735 \\
\hline
\end{tabular}

Fonte: Sinopse Estatística $(2009,2019)$ INEP

Enfatizamos o crescimento do setor privado, pois quanto mais se precariza a oferta educacional pelo setor público, com recursos insuficientes e condições de trabalho insatisfatórias, maior a possibilidade de instalação de processos de privatização da escola pública. Freitas (2012) aborda como a privatização vai sendo viabilizada.

Conforme o autor, "responsabilização e meritocracia são duas categorias, portanto, intimamente relacionadas. A terceira categoria é a da privatização”. Para Freitas, o processo 
de responsabilização e a meritocracia criam o ambiente para ampliar a privatização do sistema público de educação. Resgatamos a forma como este processo ocorre:

\begin{abstract}
Esta categoria sofreu uma verdadeira mutação na última década. O conceito de público estatal e público não estatal abriu novas perspectivas para o empresariado: a gestão por concessão. Desta forma, aquela divisão fundamental entre público e privado ficou matizada. Agora, abre-se a possibilidade do público administrado privadamente. $\mathrm{O}$ advento da privatização da gestão introduziu na educação a possibilidade de que uma escola continue sendo pública e tenha sua gestão privada (público não estatal) (PEDROSO, 2008). Continua gratuita para os alunos, mas o Estado transfere para a iniciativa privada um pagamento pela sua gestão. Há um "contrato de gestão" entre a iniciativa privada e o governo (FREITAS, 2012, p. 386, grifo nosso).
\end{abstract}

Após abordarmos o crescimento das matrículas no setor privado, buscamos identificar o nível socioeconômico das escolas da Diretoria de Ensino de Marília (DRM), a partir dos dados obtidos no site do INEP. No Painel Educacional Municipal, a dimensão Contexto apresenta o Indicador de Nível Socioeconômico (INSE) ${ }^{11}$. Conforme a Nota Técnica INSE (2015, p. 9), para melhor descrever o nível socioeconômico das escolas, "foram criados, a partir da análise de cluster por método hierárquico, seis grupos de forma que o Grupo 1 congrega as escolas com INSE médio mais baixo e o Grupo 6, com o mais alto". Resgatamos os níveis socioeconômicos dos alunos para compreendermos o que indica cada um.

O gráfico da Figura 1 indica que 20,5\% do público atendido por esta Diretoria está classificado no Grupo 3. Estes grupos indicam que as famílias possuem em sua casa bens elementares, a renda familiar mensal é entre 1 e 1,5 salários mínimos; e seus responsáveis completaram o ensino fundamental ou o ensino médio. A maioria (75.0\%) das escolas da Diretoria Regional de Marília caracteriza-se como Grupo 4 (Teste de Qui-quadrado), indicando que as famílias também possuem em sua casa os bens elementares, mas a renda familiar situa-se entre 1,5 e 3 salários mínimos; e seus responsáveis completaram o ensino médio ou a faculdade. Na comparação entre a distribuição de escolas nos seis grupos, a diferença foi significativa: Marília tem maior expressão no grupo 4 que o Estado (Teste G).

${ }^{11}$ O INSE foi calculado usando os dados da Prova Brasil e do ENEM de 2015. Cabe ressaltar que há escolas em que não foi possível calcular o indicador. 
Figura 1 - Gráfico: Indicador socioeconômico das escolas da Diretoria Regional de Marília (DRM) e da Rede Estadual (RE) segundo os grupos classificados segundo o INSE médio

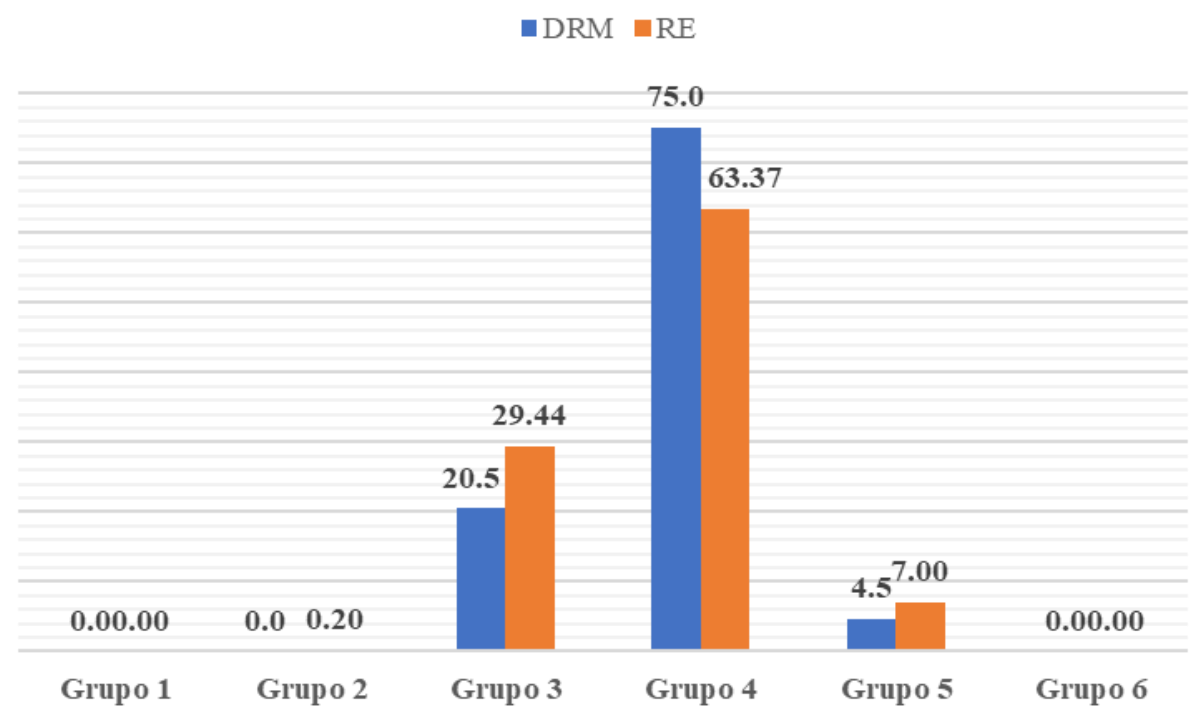

Fonte: Elaborado pelas autoras

Os dados apresentados indicam que as instituições escolares desta Diretoria atendem um público com baixo nível socioeconômico e com baixa escolaridade dos pais, que demandarão que as escolas estejam mais preparadas para atendê-los. Ernica e Batista (2011) enfatizam a necessidade de condições adequadas para os alunos que trazem poucos recursos culturais de casa. Soares (2016) afirma que o sistema educacional brasileiro deve encontrar "outras formas de atender estudantes de NSE mais baixo que trazem poucos conhecimentos escolares de casa e, portanto, dependem completamente da escola para adquirir os conhecimentos e habilidades que precisam para a vida" (SOARES, 2016, p. 775).

Portanto, o que pretendemos enfatizar com a contribuição dos autores citados é que estes dois aspectos, ou seja, o baixo nível socioeconômico e a baixa escolaridade dos pais desta DRM demandarão escolas com melhor infraestrutura e equipamentos, corpo docente qualificado e com carga horária para acompanharem e orientarem grupos de estudantes, realizarem contatos com a comunidade externa à escola, entre outros aspectos que contribuam para que as aprendizagens possam ocorrer.

Em relação à dimensão da infraestrutura das escolas da DRM, conforme apresentamos anteriormente, Soares Neto, Jesus, Karino e Andrade (2013, p. 90) criaram uma escala para medir a infraestrutura das escolas. Baseada na escala dos autores citados, a denominação de infraestrutura elementar "compreende este nível escolas que possuem somente aspectos de infraestrutura elementares para o funcionamento de uma escola, tais como água, sanitário, 
energia, esgoto e cozinha". As escolas pesquisadas possuem cozinha, sanitários, energia, coleta de lixo, esgoto e água pública, com exceção de uma escola, localizada no distrito de Avencas, no município de Marília, que não possui esgoto público, ou seja, possui fossa negra $^{12}$. Portanto, esta escola não possui os requisitos mínimos para ser considerada como infraestrutura elementar, que é a mais baixa da escala.

Informamos ainda que das 47 escolas pesquisadas, 10 (21,27\%) não possuem despensa para guarda e armazenagem de gêneros alimentícios e outros produtos, 23 (48,93\%) não possuem refeitório para servir o almoço ou lanche.

Em relação à quadra de esportes, $43(91,49 \%)$ são cobertas, $4(8,51 \%)$ não são nem coberta nem descoberta, e $11(23,40 \%)$ possuem uma quadra coberta e uma descoberta.

Em relação à questão da acessibilidade, 23 (48,93\%) possuem sala de recursos, 5 (10,63\%) possuem elevador, $24(51,06 \%)$ possuem rampa de acesso, 26 (55,31\%) possuem sanitário adequado, $3(6,38 \%)$ possuem piso direcionado, e apenas uma escola possui também porta de vão livre, sinalização tátil (piso paredes) e corrimão e guarda-copos.

O próximo nível na escala de infraestrutura é a básica. Além dos itens presentes no nível anterior, "neste nível as escolas já possuem uma infraestrutura básica, típica de unidades escolares. Em geral, elas possuem: sala de diretoria e equipamentos como TV, DVD, computadores e impressora". (SOARES NETO; JESUS; KARINO; ANDRADE, 2013, p. 90). No nível básico da escala, considerando todos os itens citados, uma escola não possui sala de diretor, 9 não possuem DVD, 12 não possuem impressora, uma não possui $\mathrm{TV}$, uma não possui computador para uso dos alunos. Destacamos que as 46 escolas que possuem computadores, apresentam um número reduzido para utilização dos alunos, considerando o número de matrículas por escola (entre 150 e 1000, conforme tabela 4). Das 46 escolas que possuem computadores para uso dos alunos, 31 escolas (67,39\%) têm entre 11 e 20 computadores, 10 escolas $(21,74 \%)$ têm menos de 10 computadores e 5 escolas $(10,87 \%)$ têm entre 21 e 30 computadores. Diante do exposto, das 47 escolas pesquisadas, 24 escolas $(51,06 \%)$ da DRM poderiam ser enquadradas como infraestrutura básica.

Pensando no próximo nível da escala de infraestrutura, apresentaremos na sequência gráficos das instalações das escolas da DRM. Informamos que todas as escolas pesquisadas possuem sala de professores.

12 Fossa Negra é um meio de saneamento bastante primitivo. Sua estrutura consiste em um buraco no solo, não necessariamente coberto, onde são levados os dejetos. Como não se trata de estanque, esse conteúdo pode vir a se infiltrar no solo, trazendo riscos de contaminação aos lençóis freáticos. 
Figura 2 - Gráfico: Salas de aulas: Escolas do Ensino Fundamental (EF) Anos Finais (AF) (DRM)

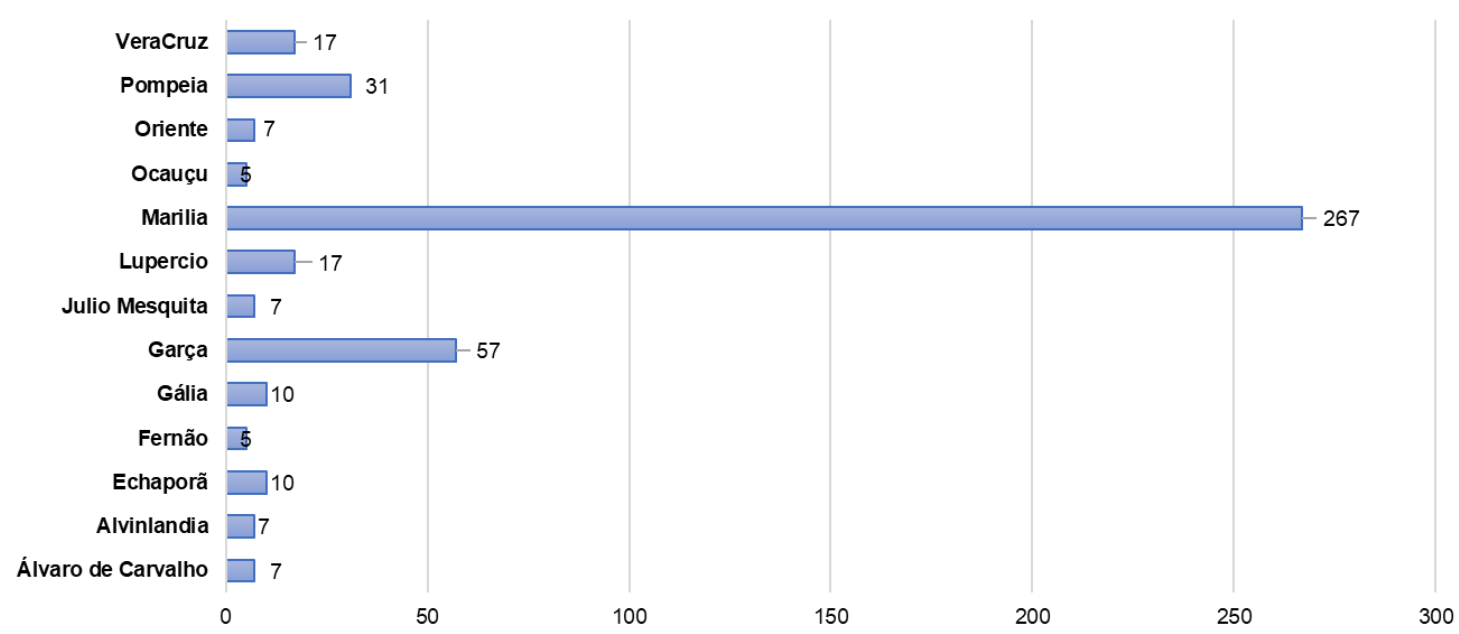

Fonte: Diretoria de Ensino de Marília (2019)

Conforme pode ser observado no gráfico da Figura 2, as cidades de Marília e Garça possuem o maior número de escolas, 27 e 06 respectivamente. O Gráfico da Figura 3 apresenta o número de salas de aula por município e a DRM possui o total de 447 salas de aula.

Figura 3 - Gráfico: Laboratórios de informática (\%) nas escolas (EF) (AF) da DRM

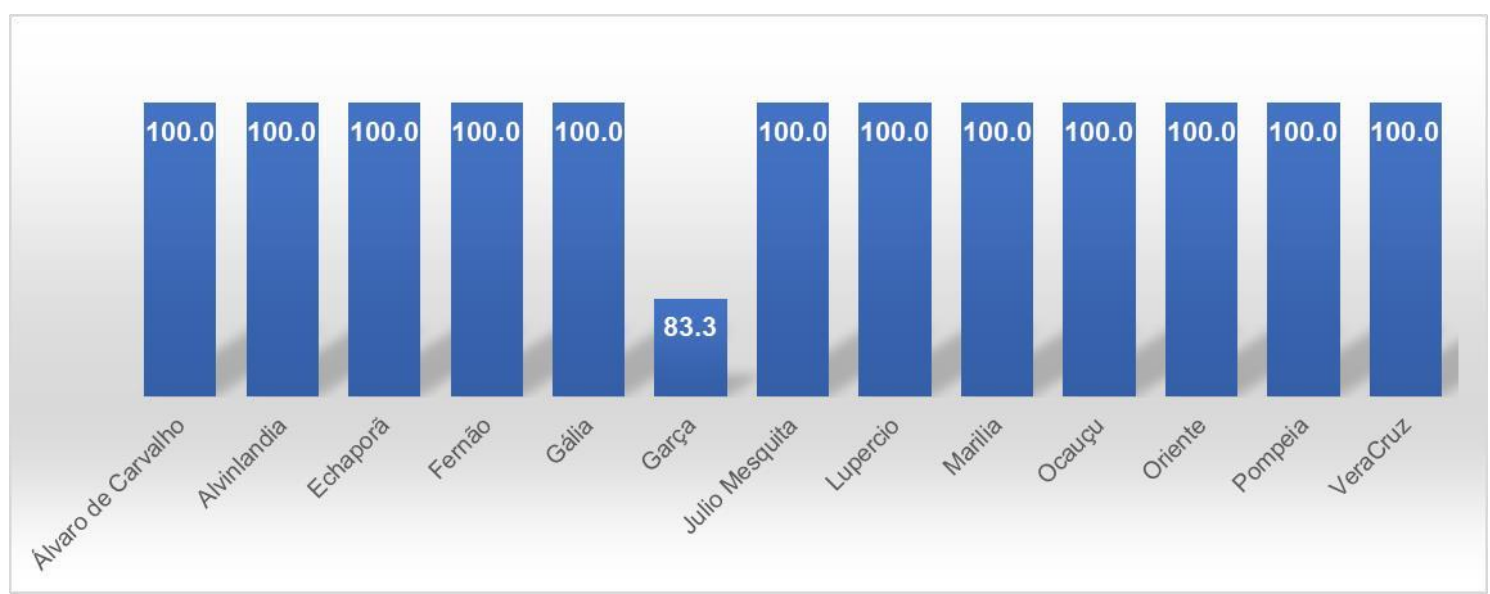

Fonte: Diretoria de Ensino de Marília (2019)

O Gráfico da Figura 3 indica que, dos municípios da DRM, apenas na cidade de Garça uma das escolas não possui laboratório de informática. Esta cidade possui seis escolas. Os demais municípios possuem laboratório de informática. 
Figura 4 - Gráfico: Laboratório de Ciências (\%) nas escolas dos anos finais do (EF) da DRM

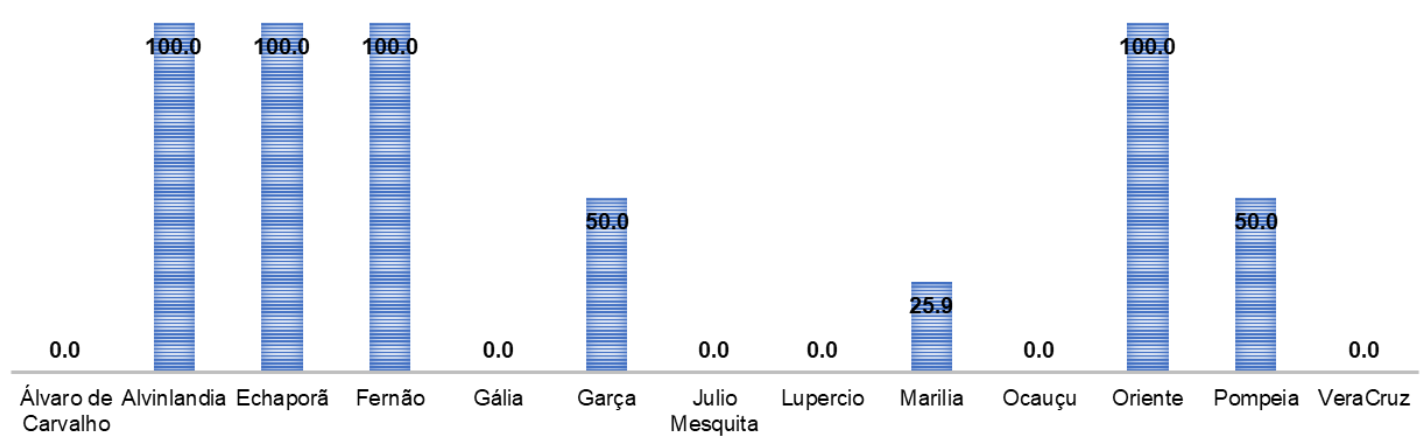

Fonte: Diretoria de Ensino de Marília (2019)

O Gráfico da Figura 4 indica que na DRM seis municípios não possuem Laboratório de Ciências em suas escolas, em Garça metade das escolas possui e em Marília apenas 25\% das escolas.

Figura 5 - Gráfico: Escolas dos anos finais do (EF) (\%) que oferecem internet para os alunos nos Municípios da DRM

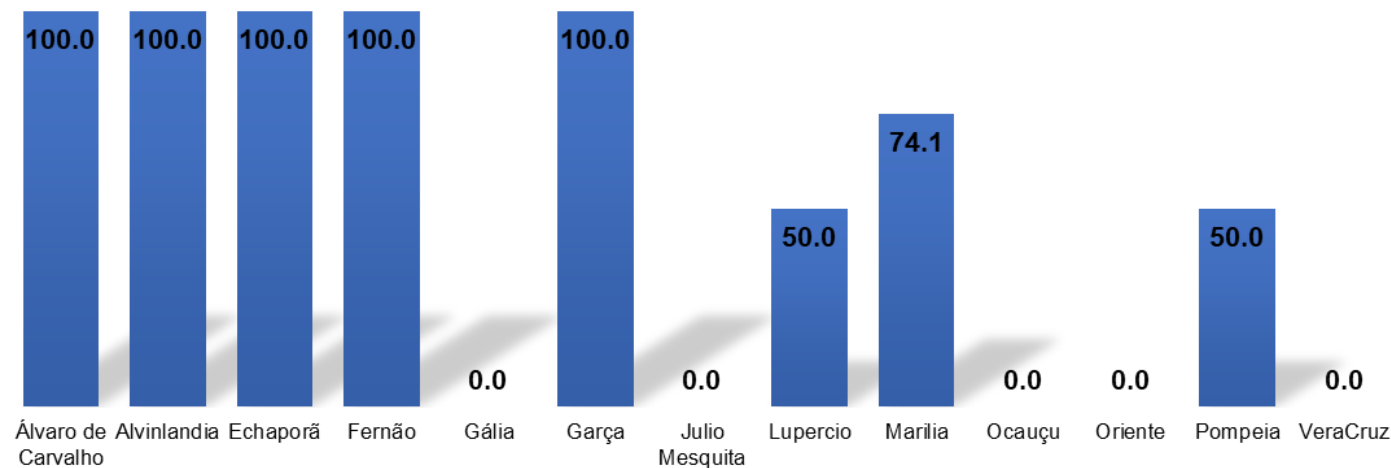

Fonte: Diretoria de Ensino de Marília (2019)

O Gráfico da Figura 5 indica que dos treze municípios da DRM, cinco municípios não oferecem internet para os alunos. Dois municípios (Lupércio e Pompéia) oferecem em apenas uma das escolas. Estes municípios possuem duas escolas cada um. O município de Marília oferece em 74,1\%, ou seja, em 20 escolas, o restante, 7 escolas, não disponibilizam internet aos alunos. Portanto, apesar de 46, ou seja, a maioria possuir laboratório de informática e computadores para uso dos alunos (embora em número reduzido), o gráfico da Figura 6 informa que 13 escolas $(27,65 \%)$ da DRM não disponibilizam internet aos alunos. 
Informamos ainda que as Escolas do Ensino Fundamental da Diretoria de Ensino da Região de Marília (DRM) não possuem biblioteca. Das 47 escolas pesquisadas, 45 escolas possuem Sala de Leitura e duas escolas localizadas em Marília não possuem nenhuma das duas. A denominação Sala de Leitura retira a exigência de contratação de um bibliotecário(a) para cada escola, o que consideramos um fator negativo, já que este profissional tem formação para a organização adequada do acervo e espaço para motivar/incentivar o interesse pela leitura, planejando contação de estórias, saraus, entre outros serviços. Com muita frequência, o responsável pela Sala de Leitura é um professor que teve algum problema de saúde e não pode estar mais na sala de aula, com formação em diversas áreas do conhecimento, o professor "readaptado". Conforme Soares et al $(2013$, p.84) [...], "a Sala de Leitura, por ser, em muitas escolas, um substituto da biblioteca. Portanto, se confunde, mas não substitui a biblioteca, que é o desejável”.

Após abordarmos estes itens de infraestrutura das escolas pesquisadas, retomamos a escala de infraestrutura (SOARES NETO; JESUS; KARINO; ANDRADE, 2013, p. 90), resgatando o próximo nível da escala:

\begin{abstract}
Adequada: além dos itens presentes nos níveis anteriores, as escolas deste nível, em geral, possuem uma infraestrutura mais completa, o que permite um ambiente mais propício para o ensino e aprendizagem. Essas escolas possuem, por exemplo, espaços como sala de professores, biblioteca, laboratório de informática e sanitário para educação infantil. Há também espaços que permitem o convívio social e o desenvolvimento motor, tais como quadra esportiva e parque infantil. Além disso, são escolas que possuem equipamentos complementares como copiadora e acesso à internet (SOARES et al., 2013, p. 90).
\end{abstract}

Mesmo desconsiderando o sanitário para educação infantil e o parque infantil, pois nosso estudo se refere aos anos finais do ensino fundamental, conforme já apontado, nenhuma escola possui biblioteca, treze não possuem acesso à internet e apenas quatro possuem copiadora. Deste modo, pelo que pudemos apreender da infraestrutura das escolas pesquisadas, utilizando a escala de infraestrutura dos autores citados, em síntese, das 47 escolas pesquisadas, $22(46,80 \%)$ possuem infraestrutura elementar, $24(51,06 \%)$ podem ser enquadradas como infraestrutura básica, nenhuma adequada, nenhuma avançada, que seria o próximo nível, e ainda, uma escola $(2,13 \%)$ que não se enquadra nem como elementar (a mais baixa da escala) por conta de não ter o esgoto público.

Cabe ressaltar que a análise considera apenas se existe ou não determinada instalação ou equipamento, e não temos informações para inferir sobre a qualidade dos itens abordados. 
Entretanto, trazemos contribuição de auditoria realizada pelo Tribunal de Contas da União (TCU) no ano de 2015. Este órgão coordenou ações integradas entre o TCU e 19 tribunais de contas regionais, realizando auditoria em 679 escolas públicas estaduais e municipais do ensino fundamental. Destacamos trecho do documento:

O conjunto examinado foi, como destacado, escolhido a partir de estudos prévios que já indicavam que as unidades escolares apresentavam baixa disponibilidade de instalações importantes para o processo ensinoaprendizagem. Em aprimoramento dos exames, as equipes técnicas aplicaram metodologia que também avaliou aspectos qualitativos da infraestrutura das escolas e, em conclusão, 59\% das 679 escolas públicas visitadas apresentaram aspectos gerais de conforto, segurança, higiene, acessibilidade e adequação ruins ou precários (BRASIL, 2015, p. 8).

O documento aponta ainda a necessidade do INEP aprimorar a coleta de dados da tabela Escola do Censo Escolar, visando qualificar os ambientes e equipamentos escolares.

[...] recomendar ao Instituto Nacional de Estudos e Pesquisas Educacionais Anísio Teixeira - Inep que aperfeiçoe o processo de coleta de dados do Censo Escolar, especialmente nos dados integrantes da tabela "escola", de forma a minimizar inconsistências entre o declarado pelo diretor da escola e a realidade, empregando, se possível, críticas na entrada de dados do sistema; dados sobre a qualidade/operacionalidade dos ambientes e equipamentos escolares; e diferenciação entre a existência de internet para uso exclusivo da administração e para uso dos alunos, no laboratório ou fora dele (BRASIL, 2015, p.12, grifo nosso).

Para finalizar a dimensão de infraestrutura das 47 escolas pesquisadas, trazemos algumas referências a esta dimensão obtidas dos professores que responderam o nosso formulário no google docs (ver anexo). Conforme mencionado anteriormente, as 47 escolas enviaram o formulário para os professores que trabalharam nos anos finais no ano de 2019, e obtivemos 191 respostas. Selecionamos algumas respostas, cada uma refere-se ao apontamento de um único professor.

"Falta de materiais adequados". (P1, 2019)

"Escola antiga precisando de reformas". (P8, 2019)

"Falta de anfiteatro, funcionário habilitado para trabalhar na biblioteca". (P25, 2019)

"Falta de espaço principalmente na biblioteca". (P29, 2019).

"Falta de computadores". (P35, 2019)

"Lousa Branca, datashow e instrumentos de trabalho de qualidade" (P67, 2019).

"Falta de computadores, piso adequado nas salas de aula e um refeitório adequado". (P98, 2019)

"Sala disponível para educação especial, internet disponível, materiais disponiveis". (P103, 2019)

"Escola com poucas salas". (P112, 2019) 
"Falta de Material didático, recursos tecnológicos insuficientes". (P124, 2019)

"Falta de lousa digital, verbas para manutenção do dia a dia na escola e infraestrutura esportiva". (P143, 2019)

"Falta de anfiteatro, funcionário habilitado para trabalhar na biblioteca". (P155, 2019)

\section{Considerações finais}

Pelo que podemos apreender das informações documentais e da coleta de dados obtida junto aos professores da dimensão infraestrutura da DRM, as escolas pesquisadas não possuem a infraestrutura adequada para que a aprendizagem possa ocorrer em um ambiente escolar mais favorável. Muito pelo contrário, as condições objetivas na dimensão de infraestrutura são precárias, o que compromete o desenvolvimento do trabalho do professor. Destacamos ainda que a infraestrutura disponível nestas escolas está distante de atingir um padrão mínimo de qualidade, conforme a lista de insumos prevista para esta etapa de ensino no Parecer 08/2010 (BRASIL, 2010), que propõe a identificação dos insumos essenciais ao desenvolvimento dos processos de ensino e aprendizagem que levem gradualmente a uma educação de qualidade. A partir desta lista de insumos, foi estabelecido o Custo Aluno Qualidade Inicial (CAQi) para cada etapa e modalidade da educação básica.

O nosso objetivo foi identificar as condições objetivas de funcionamento das escolas para fornecer subsídios para a discussão de seus resultados avaliativos na perspectiva de uma responsabilização compartilhada, ou seja, participativa, em que o poder público se reconheça no processo de melhoria da qualidade, assumindo a parte que lhe cabe, ou seja, oferecer suporte ao trabalho docente.

A agenda dos reformadores empresariais vem "aumentando a pressão sobre as escolas e seus profissionais", com a implantação de recompensas (sistema de bonificação atrelado aos resultados educacionais) e a possibilidade de sanções às escolas (repasse de verbas condicionado a resultados educacionais) e, também, encontra-se em discussão no Congresso a Lei de Responsabilidade Educacional, entre outras propostas. Portanto, cada vez mais, as escolas e seus profissionais vêm sendo culpabilizados unilateralmente pelos resultados obtidos pelos alunos nas avaliações de larga escala, sem qualquer menção às condições precárias da infraestrutura e insatisfatórias condições de trabalho dos docentes oferecidas pelo Estado.

Diante do exposto, defendemos efusivamente a importância de recuperar ou introduzir na escola um debate mais amplo sobre a qualidade, que envolva olhar tanto para as dimensões 
que a constituem, ou seja, na direção da qualidade social referenciada na formação humana, bem como as condições objetivas garantidoras da realização de seu projeto educativo, que implica não desconsiderar as questões de infraestrutura como este estudo buscou fazer, para instrumentalizar um debate mais robusto na Diretoria de Ensino estudada.

Propomos como um dos caminhos possíveis para o processo de qualificação das escolas desta rede de ensino, políticas de avaliação que se respaldem nos processos de Avaliação Institucional Participativa (AIP), nos quais os coletivos escolares se posicionam, refletem e deliberam sobre os significados e desdobramentos dos resultados obtidos, ou seja, a AIP parece muito potente para que a qualidade da escola seja de fato uma busca coletiva, compartilhada e construída pelo conjunto de atores municiados por dados que permitam maior visibilidade da realidade da escola.

Finalizamos reafirmando o perigo de estar sob a égide de políticas de avaliação educacional propostas pelos reformadores empresariais que se contentam com resultados que mais confundem do que esclarecem a complexidade do fenômeno educativo, que não se deixa capturar facilmente, e que tem provocado efeito contrário do pretendido, ou seja, melhorar a qualidade da educação. Nos Estados Unidos, a proposta dos reformadores empresariais não melhorou a educação, provocou a privatização do sistema educacional norte-americano e a destruição do magistério. Alguns autores avaliam como uma década perdida para a educação naquele país. Vamos seguir o mesmo caminho?

\section{REFERÊNCIAS}

AFONSO, A. J. Para uma conceitualização alternativa de accountability em educação. Educação \& Sociedade. Campinas, v. 33, n. 119, p. 471-484, abr./jun. 2012. Disponível em: http://www.scielo.br/pdf/es/v33n119/a08v33n119.pdf. Acesso em: 20 dez 2018.

BRASIL. CNE. Parecer CNE/CEB n. 8, de 05 de maio de 2010. Estabelece normas para aplicação do inciso IX do artigo $4^{\circ}$ da Lei n. 9.394/96 (LDB), que trata dos padrões mínimos de qualidade de ensino para a Educação Básica pública. Disponível em: http://portal.mec.gov.br/index.php?option=com_docman\&view=download\&alias=5063parecercne-seb8-. Acesso em: 20 dez. 2019.

BRASIL. INEP. Nota Técnica - Indicador de Nível Socioeconômico das Escolas Básicas (INSE). Disponível em:

http://download.inep.gov.br/informacoes_estatisticas/indicadores_educacionais/2015/nota_tec ni ca/nota_tecnica_inep_inse_2015.pdf. Acesso em: 22 fev. 2020.

BRASIL. TCU. Relatório de Auditoria, TC 025.384/2015-5. 2016. Disponível em: https:/www.tcm.pa.gov.br/portal-do-jurisdicionado/docs/resolucoes/Acordao.pdf. Acesso em: 22 jan. 2020. 
BRASIL. INEP. Sinopse estatística. 2019. Disponível em:

http://portal.inep.gov.br/web/guest/sinopses-estatisticas. Acesso em: 15 jan. 2020.

BROOKE, N. O futuro das políticas de responsabilização educacional no Brasil.

Cadernos de Pesquisa, São Paulo, v. 36, n. 128, p. 377-401, maio/ago. 2006.

BONAMINO, A.; SOUSA, S. Z. Três gerações de avaliação da educação básica no Brasil: interfaces com o currículo da/na escola. Educação e Pesquisa, São Paulo, v. 38, n. 2, p. 373-388, 2012.

ERNICA, M.; BATISTA, A. A. Educação em territórios de alta vulnerabilidade social na metrópole: um caso na periferia de São Paulo. Cenpec, São Paulo, n. 3, 2011. (Informe de pesquisa). Disponível em: https://www.cenpec.org.br/wpcontent/uploads/2015/08/Informe_de_Pesquisa3a.pdf. Acesso em: 22 jan. 2020.

FREITAS. L. C. Eliminação Adiada: o ocaso das classes populares no interior da escola e a ocultação da (má) qualidade de ensino. Educação \& Sociedade, Campinas, v. 28, n. esp. 100, p. 963-987, out. 2007.

FREITAS, L. C. Os reformadores empresariais da educação: da desmoralização do magistério à destruição do sistema público de educação. Educação \& Sociedade, Campinas, v. 33, n. 119, p. 379-404, abr./jun. 2012.

FREITAS, L. C. Políticas de Responsabilização: entre a falta de evidência e a ética. Cadernos de Pesquisa, v. 43, n. 148, p. 348-365, jan./abr. 2013. Disponível em: http://publicacoes.fcc.org.br/ojs/index.php?journal=cp\&page=article\&op=view\&path $\% 5 \mathrm{~B} \%$ 5D=266. Acesso em: $17 \mathrm{dez} .2019$.

FREITAS, L. C. A importância da avaliação: em defesa de uma responsabilização participativa. Em Aberto, Brasília, v. 29, n. 96, p. 127-139, maio/ago. 2016.

FISCHER, B. T. D. Avaliação da aprendizagem: a obsessão pelo resultado pode obscurecer a importância do processo. In: WERLE, F. O. C. (Org.) Avaliação em larga escala foco na escola. São Leopoldo: Oikos; Brasília: Líber Livro, 2010. p. 3744.

KARP, S. Desafiar a reforma escolar empresarial... e dez sinais esperançosos de resistência. Educação \& Sociedade, Campinas, v. 33, n. 119, p. 431-454, abr./jun. 2012. Disponível em: http://www.scielo.br/pdf/es/v33n119/a06v33n119.pdf. Acesso em: 20 jan. 2019.

LEHER, R. Organização, estratégia política e o Plano Nacional de Educação. Exposição apresentada no curso de especialização do MST, organizado no Coletivo CANDEEIRO e o Cento de estudo, Pesquisa e Ação em Educação Popular_CENPAEP. São Paulo, Faculdade de Educação da USP, 2014. Disponível em: https://marxismo21.org/wpcontent/uploads/2014/08/R-Leher-Estrat\%C3\%A9gia-Pol\%C3\%ADtica-e-Plano-NacionalEduca\%C3\%A7\%C3\%A3o.pdf. Acesso em: 22 jan. 2020. 
MINAYO, M. C. S. O desafio do conhecimento: pesquisa qualitativa em saúde. 7. ed. São Paulo: Hucitc; Rio de Janeiro: Abrasco, 2000.

OBNUBILAR. In: DICIO, Dicionário Online de Português. Porto: 7Graus, 2019. Disponível em: https://www.dicio.com.br/indole/. Acesso em: 2 jan. 2020.

OLIVEIRA, D. A.; PEREIRA JUNIOR; E. A. Indicadores do trabalho docente: múltiplas associações no contexto escolar. Estudos em Avaliação Educacional, São Paulo, v. 27, n. 66, p. 852-878, set./dez. 2016.

PARO, V. H. Trabalho Docente na escola de ensino fundamental: questões candentes. Cadernos de Pesquisa, São Paulo, v. 42, n. 146, p. 586-611, maio/ago. 2012.

PINTO, J. M. de R. Dinheiro traz felicidade? A relação entre insumos e qualidade na educação. Arquivos Analíticos de Políticas Educativas, v. 22, n. 19, p. 1-20, abr. 2014. Disponível em: https://epaa.asu.edu/ojs/article/view/1378/1223. Acesso em: 11 jan. 2019.

PUPO, F; SALDAÑA, P. Governo Bolsonaro muda de posição e quer Fundeb com prazo de validade de 10 anos. Jornal Folha de São Paulo, 7 fev. 2020. Disponível em: https://www1.folha.uol.com.br/educacao/2020/02/governo-bolsonaro-querpropor-novo-fundeb-com-prazo-de-validade-de-10-anos.shtml. Acesso em: $8 \mathrm{fev}$. 2020.

RAVITCH, D. Vida e morte do grande sistema escolar americano: como os testes padronizados e o modelo de mercado ameaçam a educação. Tradução Marcelo Duarte. Porto Alegre: Sulina, 2011.

SOARES NETO, J. J.; JESUS, G. R. de; KARINO, C. A.; ANDRADE, D. F. de. Uma escala para medir a infraestrutura escolar. Estudos em Avaliação Educacional, São Paulo, v. 24, n. 54, p. 78-99, 2013. Disponível em:

http://www.fcc.org.br/pesquisa/publicacoes/eae/arquivos1786/1786.pdf. Acesso em: 12 jan. 2019.

SOARES NETO, J. F.; DELGADO, V. M. S. Medida das desigualdades de aprendizagem entre estudantes do ensino fundamental. Estudos em Avaliação Educacional, São Paulo, v. 27, n. 66, p. 754-780, set./dez. 2016.

SORDI, M. R. L. A qualidade social da escola pública em confronto com a lógica dos reformadores empresariais. In: SORDI, M. R. L.; VARANI. A.; MENDES, G. S. C. V. (Org.) Qualidade(s) da Escola Pública - Reinventando a avaliação como Resistência. Uberlândia: Navegando, 2017. p. 83-100.

TOMAZ, S. C.; SILVA, M. M. O. O que as escolas fazem que os testes estandartizados desprezam na avaliação da qualidade? Ouvindo as escolas. In: SORDI, M. R. L.; VARANI. A.; MENDES, G. S. C. V. (Org.) Qualidade(s) da Escola Pública - Reinventando a avaliação como Resistência. Uberlândia: Navegando, 2017. p. 143-167. 


\section{Como referenciar este artigo}

SABIA, C. P. P.; SORDI, M. R. L. Um olhar para a dimensão infraestrutura como uma das condições objetivas possibilitadoras da qualidade em escolas públicas. Revista IberoAmericana de Estudos em Educação, Araraquara, v. 16, n. 1, p. 127-152, jan./mar. 2021. eISSN: 1982-5587. DOI: https://doi.org/10.21723/riaee.v16i1.13473

Submetido em: $23 / 03 / 2020$

Revisões requeridas: $21 / 07 / 2020$

Aprovado em: 26/08/2020

Publicado em: 02/01/2021 